\title{
Reduction of p38 mitogen-activated protein kinase and cyclooxygenase- 2 signaling by isoflurane inhibits proliferation and apoptosis evasion in human papillomavirus-infected laryngeal papillomas
}

\author{
HONGBO REN ${ }^{1 *}$, XIAOJUAN SHI ${ }^{2 *}$ and YING LI ${ }^{1}$ \\ ${ }^{1}$ Department of Otolaryngology, Children's Hospital of Zhengzhou, Zhengzhou, Henan 450000; \\ ${ }^{2}$ Department of Pediatrics, Women and Infants Hospital of Zhengzhou, Zhengzhou, Henan 450012, P.R. China
}

Received June 24, 2015; Accepted August 16, 2016

DOI: $10.3892 /$ etm.2016.3776

\begin{abstract}
Human laryngeal papilloma (LP) is a human papillomavirus-induced hyperplastic tumor of the respiratory tract, which is characterized by rapid growth and apoptosis resistance. Isoflurane (ISO) inhibits proliferation and elicits apoptosis in cancer cells. The results of the present study found that the mRNA and protein levels of cyclooxygenase-2 (COX2) were higher in LP tissues than in normal laryngeal samples, and prostaglandin $\mathrm{E}_{2}\left(\mathrm{PGE}_{2}\right)$ production was increased in LP cells, as determined by quantitative polymerase chain reaction, western blot and radioimmunoassay analyses. Notably, the increase in COX2 and $\mathrm{PGE}_{2}$ levels was significantly abrogated in the ISO-treated LP cells. The inhibitory effects of ISO on COX2 expression and activity depended on the inactivation of $\mathrm{p} 38$ mitogen-activated protein kinase (MAPK) in LP cells. By inhibiting the COX2 activity of LP cells, ISO treatment markedly suppressed cell viability and proliferation, as determined using Cell Counting Kit-8, flow cytometry and 5-ethynyl-20-deoxyuridine incorporation assays. Furthermore, ISO treatment promoted cell apoptosis, as demonstrated by flow cytometry, nucleosomal fragmentation and caspase-3 activity assays. Collectively, the present results suggest that COX2 is critical in the progression of LP, and ISO is a potential agent for LP therapy by impeding p38 MAPK/COX2 signaling.
\end{abstract}

Correspondence to: Dr Xiaojuan Shi, Department of Pediatrics, Women and Infants Hospital of Zhengzhou, 41 Jinshui Road, Zhengzhou, Henan 450012, P.R. China

E-mail:xjshisoul@163.com

*Contributed equally

Key words: human laryngeal papilloma, isoflurane, cyclooxygenase-2, p38 mitogen-activated protein kinase, proliferation, apoptosis

\section{Introduction}

Human laryngeal papilloma (LP) is a benign neoplasm mainly caused by human papillomavirus (HPV) types 6 and 11 (1). Human LP typically starts in the commissure and anterior third of the vocal folds, and subsequently affects the whole larynx, including the trachea, bronchi and lung parenchyma, thereby causing a number of morbidity and mortality cases (2). Incidence of LP is reportedly 4.3 per 100,000 among infants and 1.8 per 100,000 among adults (3). LP is characterized by recurrence of premalignant hyperplastic epithelial papillomas (4) and apoptosis resistance (5). Recurrent lesions are often observed because surgical removal of all superficial papillomatous lesions is difficult when the disease is widespread (2). Thus, developing new methods to treat LP is critical.

Epidermal growth factor receptor (EGFR) is upregulated in LP tissues (6). Multiple signaling molecules associated with EGFR are altered, including mitogen-activated protein kinases (MAPKs) and phosphatidylinositol 3-kinase (7). Previous studies revealed that cyclooxygenase-2 (COX2) expression is elevated in LP tissues and cells, accompanied by MAPK activation $(8,9)$. Phosphorylated MAPKs, including p38 MAPK, extracellular signal-regulated kinase (ERK) 1/2 and c-Jun N-terminal kinase (JNK) are implicated in the induction of COX2 expression (10). COX2 expression is mediated in part through the activation of p38 MAPK in LP cells, and the inhibition of p38 MAPK activity suppresses proliferation and enhances apoptosis of LP cells (11). Wu et al (12) demonstrated that celecoxib, a selective COX2 inhibitor, has inhibitory effects on proliferation and apoptosis evasion of LP cells, suggesting that COX2 serves a crucial function in the tumorigenesis of LP. Thus, understanding the induction of COX2 expression and activation could potentially lead to targeted treatment of HPV-infected LP.

Isoflurane (ISO) is a widely used volatile anesthetic, and previous studies have shown that ISO possesses non-anesthetic effects $(13,14)$. Notably, ISO confers anti-proliferative and proapoptotic effects on multiple human cancer cell lines (15). A previous study showed that ISO reduces COX2 expression and prostaglandin $\mathrm{E}_{2}\left(\mathrm{PGE}_{2}\right)$ release by inhibiting p38 MAPK activation in murine Kupffer cells (16). However, whether 
ISO inhibits LP malignancy by reducing p38 MAPK/COX2 signaling remains unclear.

The results of the present study show that $\mathrm{COX} 2 / \mathrm{PGE}_{2}$ biosynthesis was significantly upregulated in LP tissues and cells. The enhancement in COX 2 and $\mathrm{PGE}_{2}$ levels was markedly attenuated by ISO treatment in LP cells. Molecular mechanism analysis revealed that the inhibitory effects of ISO treatment on COX2 expression and activation were mediated by reducing p38 MAPK activation in LP cells. Moreover, ISO administration significantly hindered proliferation and prompted apoptosis of the LP cells via the reduction of COX2 activity. These results suggest that COX2 is a potential therapeutic target of LP, and ISO may be largely beneficial for LP treatment by inhibiting p38 MAPK/COX2 signaling.

\section{Materials and methods}

Reagents. Mouse anti-human COX2 (cat. no. 4842S), p38 MAPK (cat. no. 9212), ERK1/2 (cat. no. 4696), JNK (cat. no. 3708S), phosphorylated (p)-p38 MAPK (Thr180/Tyr182; cat no. 9215S), p-JNK (Thr183/Tyr185; cat. no. 9251S) and $\beta$-actin (cat. no. 3700) polyclonal antibodies were obtained from Cell Signaling Technology, Inc. (Danvers, MA, USA). Mouse anti-human p-ERK1/2 (Thr185/Tyr187; cat. no. ab76299) polyclonal antibody was purchased from Abcam (Cambridge, UK). Horseradish peroxidase-conjugated anti-mouse IgG (cat. no. AP124P) was obtained from Merck Millipore (Merck KGaA, Darmstadt, Germany). SB202190, a specific inhibitor of p38 MAPK, was purchased from Enzo Life Sciences (Plymouth Meeting, PA, USA). Celecoxib, a selective inhibitor of COX2, was obtained from Pfizer, Inc. (New York, NY, USA). ISO was purchased from Baxter International, Inc. (Deerfield, IL, USA). All other reagents were commercially obtained from Sigma-Aldrich (Merck KGaA, Darmstadt, Germany) unless otherwise stated.

Tissue specimens and cell culture. LP and adjacent normal laryngeal tissues were harvested from 5 patients who were underwent curative resection in the Children's Hospital of Zhengzhou (Zhengzhou, China). None of the patients had received chemotherapy or radiotherapy prior to surgery. Demographic information of the patients is as follows: Case 1, 4-year-old male; case 2, 4-year-old male; case 3, 6-year-old male; case 4, 8-year-old female; case 5, 1-year-old female. Biopsies were used to establish primary cell cultures or frozen in liquid nitrogen until use. Epithelial explant cultures of normal laryngeal and LP cells were established in Ham's F12 with $10 \mu \mathrm{g} / \mathrm{ml}$ hydrocortisone and $10 \mathrm{ml} / 100 \mathrm{ml}$ fetal clone II (Hyclone; GE Healthcare, Little Chalfont, UK) as previously described (17). These cultures are $>99 \%$ epithelial, based on morphology, keratin expression, and episomal HPV DNA (17). Normal laryngeal cells were expanded for $\leq 2-3$ passages, whereas LP cells were used at first passage. Cells were trypsinized and plated at $2 \times 10^{4}$ cells $/ \mathrm{cm}^{2}$ in serum-free keratinocyte growth medium (KGM; Clonetics Corp., San Diego, CA, USA), and used for experiments while subconfluent and proliferating. Experiments were performed at least thrice with cells derived from different patients unless otherwise noted. The use of human biopsies was approved by the Institutional Review Board of Women and Infants Hospital of Zhengzhou
(Zhengzhou, China). Informed consent was signed by each subject's guardian.

Experimental protocols. LP and normal laryngeal cells were cultured in KGM for $24 \mathrm{~h}$, and the cells were subsequently treated without (control) or with $1.4 \%$ ISO for $0.5 \mathrm{~h}$ at $2 \mathrm{l} / \mathrm{min}$ in a metabolic chamber (Columbus Instruments International Corporation, Columbus, OH, USA). During ISO exposure, the ISO concentration (1.4\%) was continuously verified by sampling the exhaust gas with a Datex Capnomac (Soma Technology, Inc., Bloomfield, CT, USA) (18). To investigate the inhibitory effects of SB202190 or celecoxib, cells were treated with SB202190 $(10 \mu \mathrm{M})$ or celecoxib $(5 \mu \mathrm{M})$ for $1 \mathrm{~h}$ and continuously cultured for the indicated periods.

Reverse transcription-quantitative polymerase chain reaction $(R T-q P C R)$. Total RNA was extracted from the frozen LP tissues and cultured cells using TRIzol (Invitrogen; Thermo Fisher Scientific, Inc., Carlsbad, CA, USA) following the manufacturer's protocol. The RNA $(50 \mu \mathrm{g})$ was treated with $2 \mu \mathrm{l}$ RQ1 RNase-free DNase (Promega Corporation, Madison, WI, USA) in $50 \mu \mathrm{l} 10 \mathrm{X}$ DNase buffer with $0.5 \mu \mathrm{l}$ RNase inhibitor and diethylpyrocarbonate- $\mathrm{ddH}_{2} \mathrm{O}$ (to a final volume of $50 \mu \mathrm{l}$ ) at $37^{\circ} \mathrm{C}$ for $20 \mathrm{~min}$. The concentration and quality of the RNA were measured by UV absorbance at 260 and $280 \mathrm{~nm}(260 / 280$ nm) using a Nanodrop 2000 spectrophotometer (Thermo Fisher Scientific, Inc.). Reverse transcription was performed using $3 \mu \mathrm{g}$ RNA with SuperScript ${ }^{\mathrm{TM}}$ II Reverse Transcriptase (Invitrogen), and cDNA was generated and detected by qPCR (5 $\mu$ g per reaction) using SYBR Premix Ex Taq $^{\mathrm{TM}}$ (Takara Bio, Inc., Otsu, Japan) according to the manufacturer's protocols. GAPDH was used as endogenous control. The relative mRNA level of COX2 was calculated using the $2^{-\Delta \Delta C t}$ method (19). The primers used for PCR amplification were as follows: COX2, forward, 5'-TTCTCTCGGTTAGCGACCAATT-3', and reverse, 5'-CTGAGGGCGTCTGGCTGT-3'; GAPDH, forward, 5'-GGAAATCGTGCGTGACATT-3', and reverse, 5'-CAGGCAGCTCGTAGCTCTT-3'. The amplification was performed for 35 cycles using a denaturing temperature of $94^{\circ} \mathrm{C}(1 \mathrm{~min})$, annealing temperature of $58^{\circ} \mathrm{C}(1.5 \mathrm{~min})$, and extension temperature of $72^{\circ} \mathrm{C}(1.5 \mathrm{~min})$. Results were analyzed using ABI 7500 Real-Time PCR System software v2.0.1 (Applied Biosystems; Thermo Fisher Scientific, Inc.).

Measurement of $P G E_{2}$ production. At $24 \mathrm{~h}$ after the LP or normal laryngeal cells were treated with ISO or celecoxib or SB202190, $\mathrm{PGE}_{2}$ production was quantified in the culture medium from $1 \times 10^{5}$ LP or normal laryngeal cells. $\mathrm{PGE}_{2}$ was measured using a radioimmunoassay (RIA) kit (Amersham Biosciences Europe GmbH; GE Healthcare, Freiburg, Germany) as previously described (20). The experiments were performed in triplicate.

Western blot analysis. The frozen tissues and cultured cells were lysed in RIPA lysis buffer (Beyotime Institute of Biotechnology, Haimen, China). For tissues, $\sim 1 \mathrm{ml}$ RIPA lysis buffer was added to $100 \mathrm{mg}$ tissues and homogenized on ice. For cells, cells in the 6-well plates were washed with $2 \mathrm{ml}$ phosphate-buffered saline (PBS; Beyotime Institute of Biotechnology) twice and then treated with $100 \mu \mathrm{l} /$ well RIPA lysis buffer on ice for $30 \mathrm{~min}$. The 
homogenates or cell lysates were sonicated on ice (five times for $5 \mathrm{sec}$ each at $40 \mathrm{~W}$, with 20-sec intervals between each sonication) with a Braun Labsonic 2000 microtip sonifier (Braun, Melsungen, Germany) and centrifuged at 12,000 x $g$ for $10 \mathrm{~min}$ at $4^{\circ} \mathrm{C}$. The protein concentration of the extracts was measured by the bicinchoninic acid method (Pierce Biotechnology; Thermo Fisher Scientific, Inc., Rockford, IL, USA). Samples containing equal amounts of proteins $(25 \mu \mathrm{g})$ were boiled in sodium dodecyl sulfate (SDS) sample buffer and then analyzed by $10 \%$ SDS-polyacrylamide gel electrophoresis (Beyotime Institute of Biotechnology). The proteins were electrotransferred to nitrocellulose membranes (Merck Millipore), and blocked with $5 \%$ non-fat milk in Tris-buffered saline $(50 \mathrm{mM}$ Tris- $\mathrm{HCl} \mathrm{pH} \mathrm{7.4,} 150 \mathrm{mM} \mathrm{NaCl}$ ) and $0.1 \%$ Tween 20 (TBST) with shaking at room temperature for $1 \mathrm{~h}$. Membranes were incubated with primary antibodies targeting COX2 $(1: 2,000)$, p38 MAPK (1:1,500), ERK1/2 (1:1,000), JNK (1:1,000), p-p38 MAPK (Thr180/Tyr182; 1:1,000), p-ERK1/2 (Thr185/Tyr187; 1:1,000), p-JNK (Thr183/Tyr185; 1:1,000) and $\beta$-actin $(1: 2,000)$ overnight at $4^{\circ} \mathrm{C}$. After washing with TBST thrice, 5 min per time, the membranes were incubated with horseradish peroxidase-conjugated secondary antibody $(1: 2,000)$ in TBST at room temperature for $1 \mathrm{~h}$. Equal sample loading was confirmed using $\beta$-actin. Protein expression was detected by chemiluminescent film (Amersham Biosciences) using an enhanced chemiluminescence assay kit (Pierce Biotechnology). The protein bands were quantified using Quantity One software v4.62 (Bio-Rad Laboratories, Inc., Hercules, CA, USA).

Cell viability assay. At $24 \mathrm{~h}$ after LP cells were treated with ISO or celecoxib, the number of viable cells was determined using a Cell Counting kit-8 (CCK-8; Dojindo Molecular Technologies, Inc., Kumamoto, Japan), according to the manufacturer's instructions. In brief, cells were seeded in 96-well plates at a concentration of $1 \times 10^{3}$ per well and cultured for 1 , 2, 3 and 4 days. CCK-8 solution $(10 \mu \mathrm{l})$ was added into each well at the indicated time points, then the plates were stored for $2 \mathrm{~h}$ at $37^{\circ} \mathrm{C}$. A scanning multi-well spectrometer (Bio-Tek Instruments, Inc., Winooski, VT, USA) was used to measure the absorbance at $450 \mathrm{~nm}$.

5-Ethynyl-20-deoxyuridine (EdU) incorporation assay. At $24 \mathrm{~h}$ after LP cells were treated with ISO or celecoxib, $50 \mu \mathrm{M}$ EdU was added and the cells were incubated for $2 \mathrm{~h}$, then fixed with $4 \%$ paraformaldehyde for $20 \mathrm{~min}$ at room temperature. Subsequently, the cells were incubated with reaction buffer (0.5\% Triton X-100; Guangzhou RiboBio Co., Ltd., Guangzhou, China) for $30 \mathrm{~min}$. After washing twice with cold PBS, cells were counterstained with 4',6-diamidino-2-phenylindole (Beyotime Institute of Biotechnology). Six random fields were selected for observation and then photographed under an inverted fluorescent microscope (Carl Zeiss AG, Oberkochen, Germany).

Cell cycle analysis. At $24 \mathrm{~h}$ after the LP cells were treated with ISO or celecoxib, the cells were washed with PBS, fixed with ice-cold $70 \%$ ethanol and treated with $1 \mathrm{mg} / \mathrm{ml}$ RNase for $30 \mathrm{~min}$ at $37^{\circ} \mathrm{C}$. DNA content staining was performed with $50 \mu \mathrm{g} / \mathrm{ml}$ propidium iodide (PI) at $4^{\circ} \mathrm{C}$ in the dark for 30 min. A FACSCalibur flow cytometer (BD Biosciences, Franklin Lakes, NJ, USA) was utilized for data measurement, and the data were analyzed using CellQuest Pro software (BD Biosciences).

Apoptosis assay by flow cytometry. For apoptosis assessment, Annexin V-fluorescein isothiocyanate (FITC) and PI staining was performed as previously described (21). In brief, at $24 \mathrm{~h}$ after LP cells were treated with ISO or celecoxib, the cells were harvested, centrifuged at $10,000 \times \mathrm{g}$ and $4^{\circ} \mathrm{C}$ for $5 \mathrm{~min}$ and resuspended in binding buffer (BD Biosciences). Annexin V-FITC (10 $\mu \mathrm{l}$; BD Biosciences) was added, incubated at room temperature for $15 \mathrm{~min}$, and counterstained with $5 \mu \mathrm{l}$ PI for $30 \mathrm{~min}$. Annexin V-FITC and PI fluorescence was analyzed using a FACSCalibur flow cytometer and the results were analyzed using CellQuest software.

Nucleosomal fragmentation assay. At $24 \mathrm{~h}$ after LP cells were treated with ISO or celecoxib, cell apoptosis was measured using a nucleosomal fragmentation kit (Cell Death Detection ELISA PLUS; Roche Applied Science, Penzberg, Germany) as previously described (16). The absorbance values were normalized against those from control-treated cells to derive a nucleosomal enrichment factor.

Quantitative caspase-3 activity assay. Caspase-3 activity was detected using a Caspase-3/CPP32 Colorimetric Assay kit (BioVision, Inc., Palo Alto, CA, USA) as previously described (16). Briefly, at $24 \mathrm{~h}$ after LP cells were treated with ISO or celecoxib, $1 \times 10^{6}$ cells were incubated with $50 \mu \mathrm{l}$ chilled lysis buffer on ice for $10 \mathrm{~min}$. The supernatant was then collected after $10,000 \times \mathrm{g}$ centrifugation at $4^{\circ} \mathrm{C}$ for $10 \mathrm{~min}$. Protein $(150 \mu \mathrm{g})$ was added to $50 \mu \mathrm{l} 2 \mathrm{X}$ reaction buffer containing $5 \mu \mathrm{l}$ $\mathrm{N}$-acetyl-Asp-Glu-Val-Asp-pNA substrate (final concentration, $200 \mu \mathrm{M}$ ). N-acetyl-Asp-Glu-Val-Asp-pNA cleavage was monitored by detecting enzyme-catalyzed release of pNA at $405 \mathrm{~nm}$ after incubation at $37^{\circ} \mathrm{C}$ for $2 \mathrm{~h}$ using a microplate reader (Bio-Tek instruments, Inc.).

Statistical analysis. All values are expressed as the mean \pm standard derivation. Intergroup differences were determined by Student's two-tailed unpaired $t$-test or one-way analysis of variance, followed by Dunnett's post hoc test as appropriate. GraphPad v5.0 statistical software (GraphPad Software, Inc., San Diego, CA, USA) was used to perform data analysis. $\mathrm{P}<0.05$ was considered to indicate a statistically significant difference.

\section{Results}

COX2 expression and $P G E_{2}$ production are increased in $L P$ tissues. The mRNA and protein levels of COX2 in LP tissues and normal laryngeal biopsies were evaluated using RT-qPCR and western blot analyses, respectively. As shown in Fig. 1A, the COX2 mRNA expression level was elevated by approximately fivefold $(\mathrm{P}<0.05)$ in LP tissues compared with normal laryngeal tissues. Furthermore, COX2 protein expression was significantly higher in LP tissues than that in normal laryngeal biopsies $(\mathrm{P}<0.01$; Fig. $1 \mathrm{~B}$ and $\mathrm{C})$. Consistently, the mRNA and protein levels of COX2 were significantly increased in cultured LP cells derived from LP tissues compared with the normal cells isolated from normal 
A

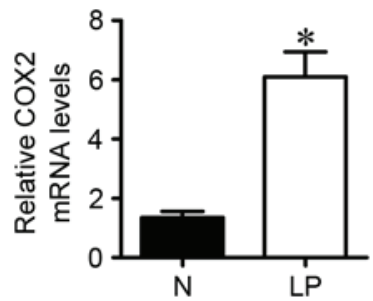

D

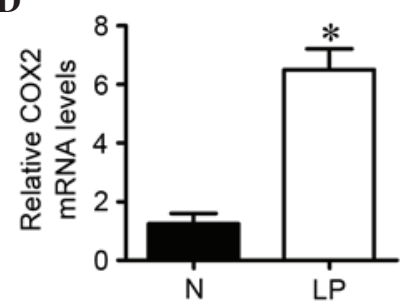

B

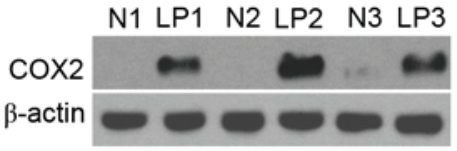

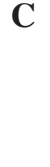
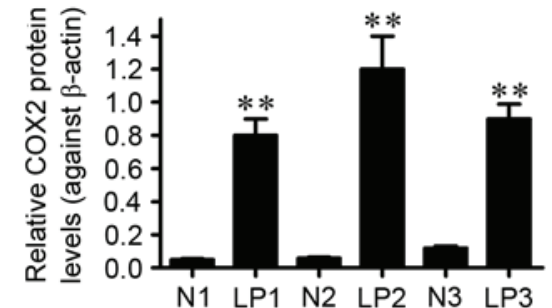

Figure 1. COX2 expression and $\mathrm{PGE}_{2}$ production were increased in LP cells. (A) COX2 mRNA levels were analyzed using reverse transcription-quantitative polymerase chain reaction (RT-qPCR) in LP and N tissues. GAPDH was used as endogenous control. (B) Western blotting was performed to detect the protein expression of COX2. Results shown were from three paired LPs and N tissues. $\beta$-actin was used as internal control. (C) Relative protein expression of COX2 was quantified and normalized against $\beta$-actin. (D) RT-qPCR was used to analyze the mRNA expression of COX2 in isolated cells from LP and N tissues (E) Representative western blot results of COX2 protein expression in LP and N cells. (F) Relative protein expression of COX2 was quantified and normalized against $\beta$-actin. (G) Radioimmunoassay was performed to assess $\mathrm{PGE}_{2}$ production in LP and $\mathrm{N}$ cells. Representative data are from three independent experiments and expressed as mean \pm standard deviation. ${ }^{*} \mathrm{P}<0.05,{ }^{* *} \mathrm{P}<0.01$ vs. $\mathrm{N}$ group. COX2, cyclooxygenase 2 ; $\mathrm{N}$, normal laryngeal tissues or cells; LP, laryngeal papilloma tissues or cells; $\mathrm{PGE}_{2}$, prostaglandin $\mathrm{E}_{2}$.

A

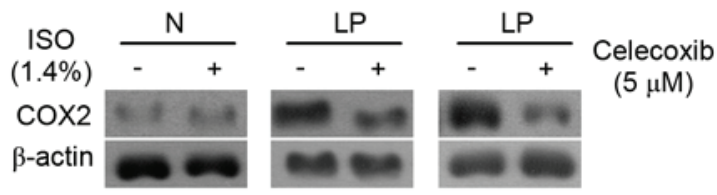

B
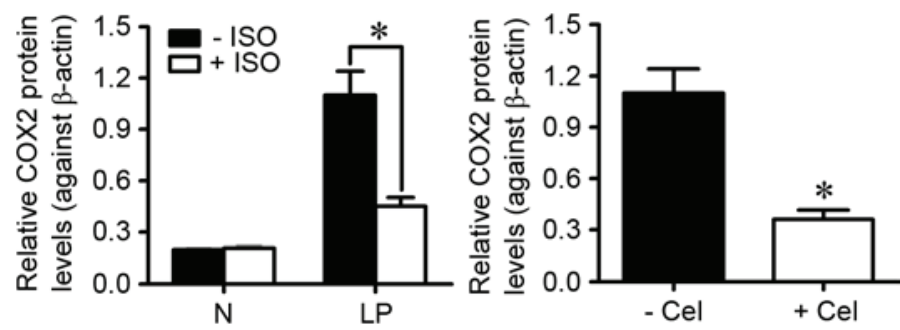

C
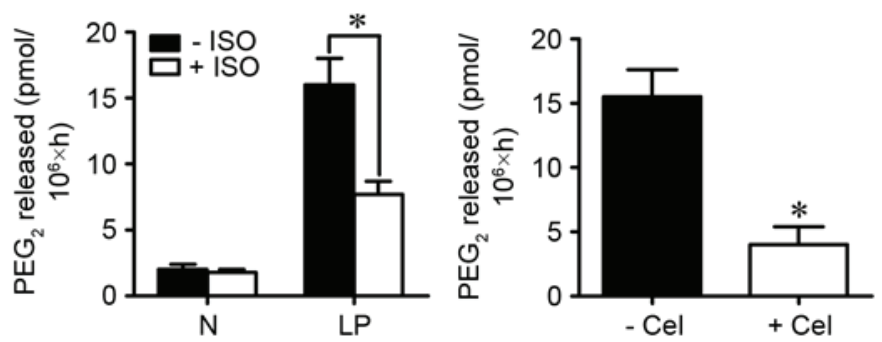

Figure 2. ISO treatment inhibited COX2/PGE 2 generation in LP cells. LP and $\mathrm{N}$ cells were treated with $1.4 \%$ ISO for $0.5 \mathrm{~h}$ or subjected to $5 \mu \mathrm{M}$ celecoxib treatment for $1 \mathrm{~h}$. The cells were then continuously cultured for $24 \mathrm{~h}$. (A) Protein levels of COX2 were determined by western blot analysis. $\beta$-actin was used as internal control. (B) COX2 protein expression was quantified and normalized against $\beta$-actin. (C) $\mathrm{PGE}_{2}$ production in $\mathrm{LP}$ and $\mathrm{N}$ cells was measured using a radioimmunoassay. Representative data are from three independent experiments and expressed as the mean \pm standard deviation. " $\mathrm{P}<0.05$. COX2, cyclooxygenase 2; N, normal laryngeal cells; LP, laryngeal papilloma cells; ISO, isoflurane; Cel, celecoxib; $\mathrm{PGE}_{2}$, prostaglandin $\mathrm{E}_{2}$.

laryngeal tissues (Fig. 1D-F). $\mathrm{PGE}_{2}$ production, an indicator of COX2 activity, was measured by RIA in LP and normal laryngeal cells. As shown in Fig. 1G, $\mathrm{PGE}_{2}$ level was eightfold $(\mathrm{P}<0.01)$ higher in LP cells than that in normal cells, which was in accordance with the expression tendency of COX2.
These results suggest that COX2 expression and $\mathrm{PGE}_{2}$ generation are increased in LP.

ISO reduces COX2/PGE 2 biosynthesis in LP cells. Wang et al (16) demonstrated that ISO reduces COX2 
A

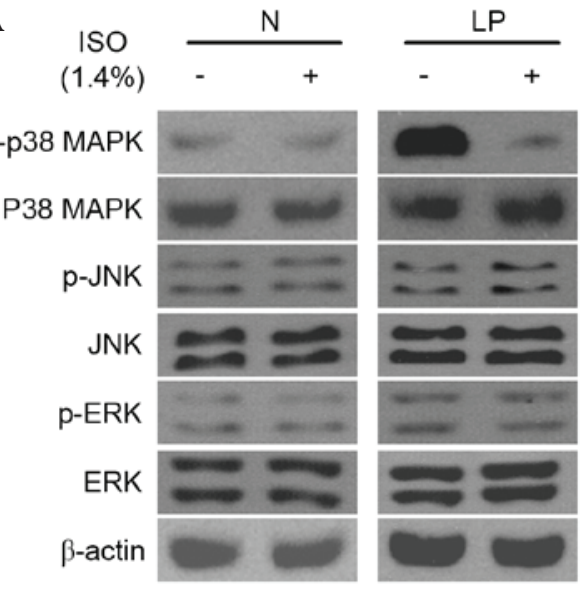

D

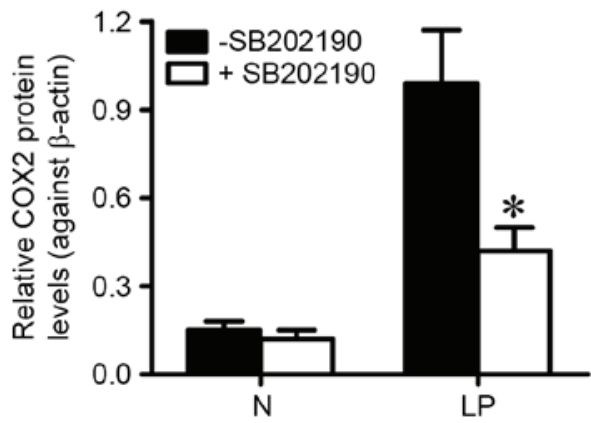

B

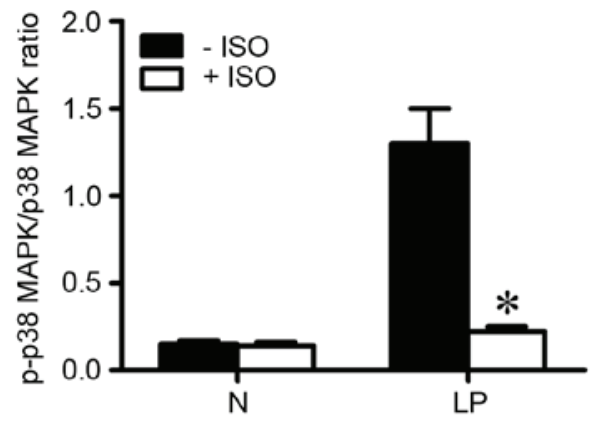

C

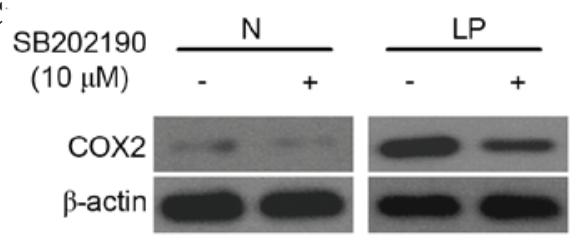

E

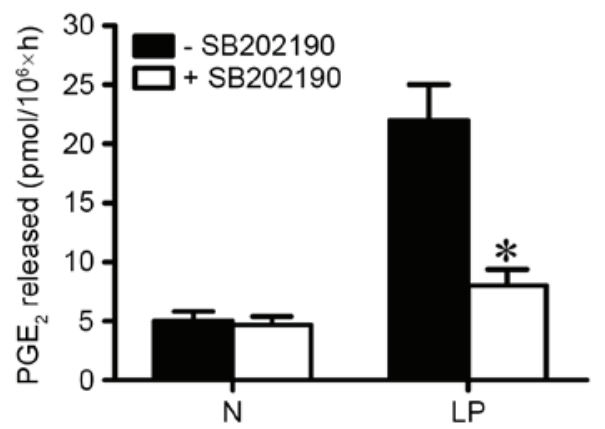

Figure 3. ISO treatment inhibited COX2 expression and $\mathrm{PGE}_{2}$ production via inactivation of p38 MAPK in LP cells. (A) LP and N cells were treated with or without $1.4 \%$ ISO for $0.5 \mathrm{~h}$. The cells were continuously cultured for $6 \mathrm{~h}$. Western blot analysis was performed to assess the phosphorylation of p38 MAPK, ERK1/2 and JNK. $\beta$-actin was used as internal control. (B) Ratio of p-p38 MAPK to p38 MAPK is indicated above the bands. (C) LP and N cells were treated with or without $10 \mu \mathrm{M} \mathrm{SB} 202190$ for $1 \mathrm{~h}$ and then washed by PBS. At $24 \mathrm{~h}$ after SB202190 treatment, western blot analysis was used to analyze the protein expression of COX2. $\beta$-actin was used as internal control. (D) COX2 expression in was quantified and normalized against $\beta$-actin. (E) LP and N cells were treated with or without $10 \mu \mathrm{M} \mathrm{SB} 202190$ for $1 \mathrm{~h}$. At $24 \mathrm{~h}$ after SB202190 treatment, the quantity of PGE $_{2}$ in the culture medium was determined by radioimmunoassay. Representative data are from three independent experiments and expressed as the mean \pm standard deviation. ${ }^{*} \mathrm{P}<0.05$. ISO, isoflurane; $\mathrm{N}$, normal laryngeal tissues or cells; LP, laryngeal papilloma tissues or cells; p38 MAPK, p38 mitogen-activated protein kinase; JNK, c-Jun N-terminal kinase; ERK, extracellular signal-regulated kinase; $\mathrm{COX} 2$, cyclooxygenase $2 ; \mathrm{PGE}_{2}$, prostaglandin $\mathrm{E}_{2}$.

expression and $\mathrm{PGE}_{2}$ release in Kupffer cells. We investigated whether ISO treatment inhibited COX2 expression and $\mathrm{PGE}_{2}$ production in LP and normal laryngeal cells. As shown in Fig. 2A and B, the expression of COX2 was nearly threefold $(\mathrm{P}<0.05)$ lower in ISO-treated LP cells than in control LP cells. Alternatively, ISO treatment had no effect on COX2 expression in normal laryngeal cells. $\mathrm{PGE}_{2}$ production was significantly decreased by ISO treatment in LP cells but did not change in normal laryngeal cells (Fig. 2C). As a positive control, celecoxib administration also decreased $\mathrm{COX} 2 / \mathrm{PGE}_{2}$ biosynthesis in LP cells (Fig. 2A-C). These results indicate that ISO treatment counteracts the increase in COX2 expression and $\mathrm{PGE}_{2}$ production in LP cells.

ISO reduces $C O X 2$ expression and activity by inactivating p38 MAPK in LP cells. MAPK activation has been implicated to be involved in the upregulation of COX2 (10). The present study investigated whether ISO treatment hindered COX2 expression and $\mathrm{PGE}_{2}$ production by reducing $\mathrm{p} 38$ MAPK activation in LP cells. Western blot results showed that ISO treatment significantly reduced the phosphorylation of p38 MAPK (Thr180/Tyr182) but not those of ERK1/2 (Thr185/Tyr187) and JNK (Thr183/Tyr185) in LP cells (Fig. 3A and B). However, ISO treatment had no effect on phosphorylation of MAPKs in normal laryngeal cells (Fig. 3A and B). In addition, it was found that treatment with $10 \mu \mathrm{M}$ SB202190 for $1 \mathrm{~h}$, which is a p38 MAPK activation inhibitor, led to a notable reduction of $\mathrm{COX} 2$ expression in LP cells (Fig. 3C and D). Furthermore, $\mathrm{PGE}_{2}$ production was significantly reduced in SB202190-treated LP cells (Fig. 3E). These findings indicate that ISO treatment reduces COX2 expression and activity in LP cells by inhibiting p38 MAPK activation.

ISO inhibits LP cell proliferation by decreasing COX2 activity. COX2 activity is involved in increased proliferation of LP cells (11). To investigate whether the inhibitory effects of ISO on LP cell viability and proliferation depend on the reduction of COX2 activity, CCK-8, flow cytometry and EdU incorporation assays were performed. As shown in Fig. 4A, ISO administration significantly reduced the viability of LP cells. Cell cycle was arrested at the G1 phase, with $66 \%$ of 

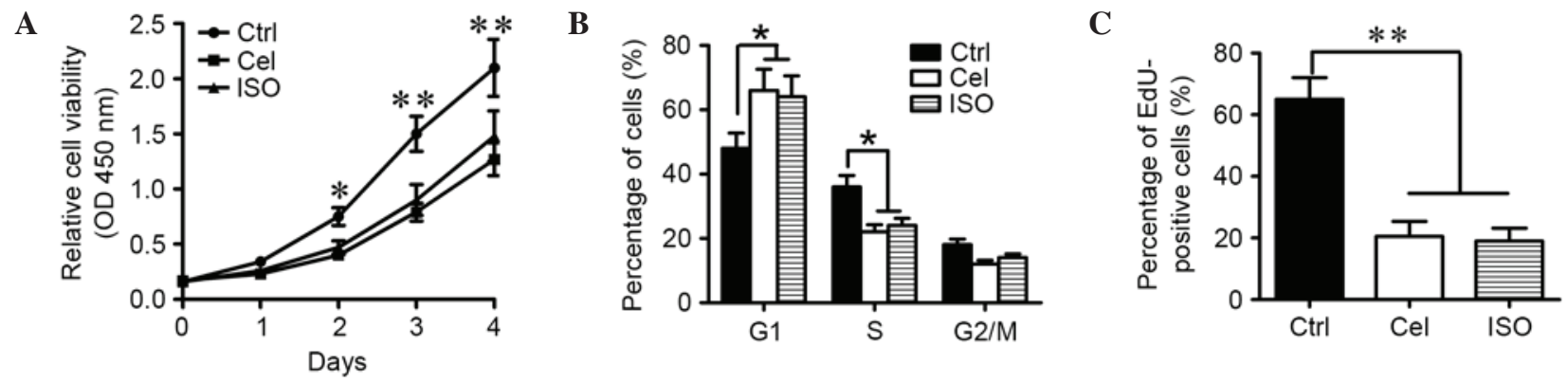

Figure 4. ISO treatment inhibited the proliferation of LP cells by reducing COX2 activity. LP cells were treated with $1.4 \%$ ISO for $0.5 \mathrm{~h}$ or subjected to $5 \mu \mathrm{M}$ celecoxib for $1 \mathrm{~h}$, and the cells were continuously cultured for $24 \mathrm{~h}$. (A) CCK-8 assay was used to detect the viability of LP cells. (B) Flow cytometry analysis depicted cell cycle distribution of LP cells. (C) EdU incorporation assay was performed to examine the proliferation of LP cells. Representative data are from three independent experiments and expressed as the mean \pm standard deviation. ${ }^{*} \mathrm{P}<0.05,{ }^{* *} \mathrm{P}<0.01$ vs. Ctrl group. LP, laryngeal papilloma; OD, optical density; Ctrl, Control group; ISO, isoflurane; Cel, celecoxib; EdU, 5-ethynyl-20-deoxyuridine.

A

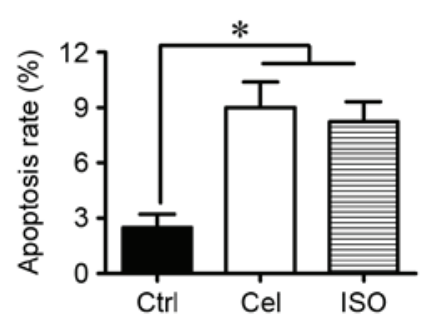

B

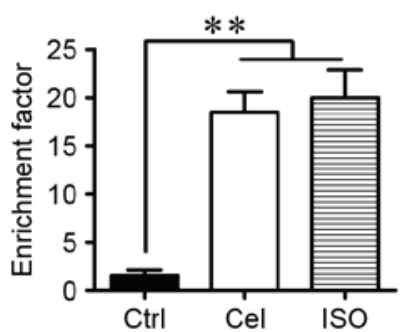

C

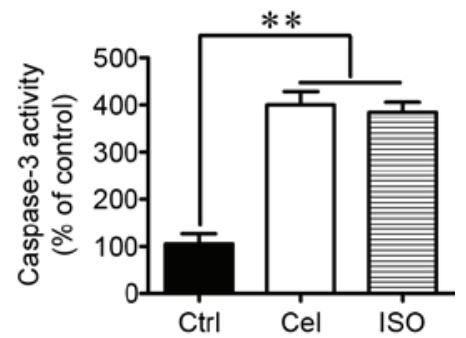

Figure 5. ISO treatment promoted the apoptosis of LP cells by inhibiting cyclooxygenase 2 activity. LP cells were treated with $1.4 \%$ ISO for 0.5 h or subjected to $5 \mu \mathrm{M}$ celecoxib for $1 \mathrm{~h}$, and the cells were continuously cultured for $24 \mathrm{~h}$. (A) Apoptotic rate of LP cells was measured by flow cytometry. (B) Nucleosomal fragmentation assay was performed to detect LP cell apoptosis. (C) Caspase-3 activity was used to assess the apoptosis of LP cells. Representative data are from three independent experiments and expressed as the mean \pm standard deviation. ${ }^{*} \mathrm{P}<0.05,{ }^{* *} \mathrm{P}<0.01$ vs. Ctrl group. LP, laryngeal papilloma; Ctrl, Control group; ISO, isoflurane; Cel, celecoxib.

ISO-treated LP cells in G0/G1 compared with $48 \%$ of control cells $(\mathrm{P}<0.05$; Fig. 4B). The percentage of EdU incorporation was also decreased, with $22 \%$ of ISO-treated LP cells compared with $64 \%$ of control cells $(\mathrm{P}<0.01$; Fig. $4 \mathrm{C})$. All these results were consistent with the inhibitory effects of celecoxib on LP cell viability and proliferation (Fig. 4A-C), suggesting that ISO treatment inhibits the viability and proliferation of LP cells, probably by reducing COX 2 activity.

ISO promotes LP cell apoptosis by inhibiting COX2 activity. Increase in COX2 activity has been shown to inhibit LP cell apoptosis (12). Flow cytometry, nucleosomal fragmentation and caspase- 3 activity assays were employed to investigate whether ISO induced LP cell apoptosis by inhibiting COX2 activity. Flow cytometry analysis showed that ISO treatment significantly increased the percentage of apoptotic LP cells compared with the control cells (Fig. 5A). The significant increases in nucleosomal fragmentation and caspase-3 activity were observed in ISO-treated LP cells compared with the control cells (Fig. 5B and C). The above results were consistent with the proapoptotic effects of celecoxib on LP cells (Fig. 5). Thus, ISO administration promotes the apoptosis of LP cells probably by inhibiting COX2 activity.

\section{Discussion}

Cultured LP cells are a model system for the study of HPV-infected LP. In contrast to immortalized cell lines, these primary cells closely reflect the biology of in vivo papilloma.
In the present report, it was found that ISO treatment significantly inhibited proliferation and prompted apoptosis in LP cells by reducing p38 MAPK/COX2 signaling. The key findings are as follows: First, COX2 was highly expressed in LP tissues and cells compared to normal laryngeal tissues and cells. Second, ISO treatment significantly inhibited COX2 expression and $\mathrm{PGE}_{2}$ production in LP cells. Third, the inhibitory effects of ISO on COX2 expression and activity depend on the inactivation of p38 MAPK in LP cells. Finally, ISO markedly decreased the proliferation and apoptosis resistance of LP cells by inhibiting COX2 activity.

COX2, an inducible enzyme, serves a crucial function in the production of prostaglandins under physiological and pathophysiological conditions, which can be rapidly induced by various stimulants, such as growth factors, carcinogens and proinflammatory cytokines (22). COX2 expression is enhanced in a variety of inflammatory and neoplastic diseases (23). Notably, COX2 expression is upregulated in numerous types of HPV-infected cells, including respiratory papillomas (24), head and neck tumors (25-27), cervical cancers and penile cancers $(28,29)$. Wu et al $(11)$ reported that COX2 upregulation is mediated in part by Rac1-dependent activation of p38 MAPK in papilloma cells. Wang et al (16) demonstrated that ISO administration markedly decreased COX2 expression via the inhibition of p38 MAPK activation in zymosan-stimulated murine Kupffer cells. The present results showed that ISO treatment significantly suppressed COX2 expression and activity by inhibiting p38 MAPK activation. 
Activation of p38 MAPK can exert either proapoptotic or antiapoptotic effects in different cell types and cell microenvironments (30). p38 MAPK activation has been shown to increase cell viability in LP cells (11). This effect may be due to the increased levels of COX2 induced by $\mathrm{p} 38$ MAPK activation (12). Previous studies showed that COX2 upregulation enhances proliferation and apoptosis resistance, and inactivation of COX2 induces cell apoptosis in cancer cells (31-33). Treatment with celecoxib, an inhibitor of COX2, could effectively suppress cell proliferation and induce cell apoptosis in LP cells, and these effects are mediated in part by $\mathrm{PGE}_{2}(12)$. Notably, excessive production of $\mathrm{PGE}_{2}$ has been reported to promote cell proliferation and inhibit cell apoptosis (34). ISO inhibits proliferation of several human cancer cell lines (15). The present results showed that ISO treatment markedly decreased LP cell viability and proliferation by inhibiting COX2 activity. Additionally, ISO has been demonstrated to induce apoptosis in different cell types $(35,36)$, and prolonged ISO treatment can induce apoptosis in cancer cells (15). A previous study suggested that the effect of ISO on apoptosis depends on the mitochondrial pathway (37), which is regulated by Bcl-2 family proteins; this pathway also involves the release of cytochrome $c$ from the mitochondria to the cytosol (38). The released cytochrome $c$ activates caspase-9, and consequently induces caspase-3 activation, ultimately leading to cell apoptosis (39). Thus, the present findings showed that ISO treatment significantly increased LP cell apoptosis by inhibiting COX2 activity.

In summary, the present study showed that $\mathrm{COX} 2$ is highly expressed in HPV-infected LP tissues and cells compared with normal laryngeal tissues and cells, and $\mathrm{PGE}_{2}$ production is increased in LP cells. Notably, it was found that ISO treatment significantly reduces COX2 enhancement and $\mathrm{PGE}_{2}$ release in LP cells by inhibiting the activation of p38 MAPK. In addition, ISO significantly inhibits cell proliferation and apoptosis resistance by inhibiting COX2 activity. Collectively, ISO may be a potential agent for LP treatment by inhibiting $\mathrm{p} 38 \mathrm{MAPK} / \mathrm{COX} 2$ activation.

\section{References}

1. Watanabe A, Tsujie H, Taniguchi M, Hosokawa M, Fujita M and Sasaki S: Laryngoscopic detection of pharyngeal carcinoma in situ with narrowband imaging. Laryngoscope 116: 650-654, 2006.

2. Katsenos S, and Becker HD: Respiratory papillomatosis: A rare chronic disease, difficult to treat, with potential to lung cancer transformation: Apropos of two cases and a brief literature review. Case Rep Oncol 4: 162-171, 2011.

3. Katada C, Nakayama M, Tanabe S, Koizumi W, Masaki T, Takeda M, Okamoto M and Saigenji K: Narrow band imaging for detecting metachronous superficial oropharyngeal and hypopharyngeal squamous cell carcinomas after chemoradiotherapy for head and neck cancers. Laryngoscope 118: 1787-1790, 2008.

4. Steinberg BM, Meade R, Kalinowski S and Abramson AL: Abnormal differentiation of human papillomavirus-induced laryngeal papillomas. Arch Otolaryngol Head Neck Surg 116: 1167-1171, 1990.

5. Poetker DM, Sandler AD, Scott DL, Smith RJ and Bauman NM: Survivin expression in juvenile-onset recurrent respiratory papillomatosis. Ann Otol Rhinol Laryngol 111: 957-961, 2002.

6. Johnston D, Hall H, DiLorenzo TP, and Steinberg BM: Elevation of the epidermal growth factor receptor and dependent signaling in human papillomavirus-infected laryngeal papillomas. Cancer Res 59: 968-974, 1999.
7. Zhang $\mathrm{P}$ and Steinberg BM: Overexpression of PTEN/MMAC1 and decreased activation of Akt in human papillomavirus-infected laryngeal papillomas. Cancer Res 60: 1457-1462, 2000.

8. Vambutas A, Di Lorenzo TP and Steinberg BM: Laryngeal papilloma cells have high levels of epidermal growth factor receptor and respond to epidermal growth factor by a decrease in epithelial differentiation. Cancer Res 53: 910-914, 1993.

9. Johnston D, Hall H, DiLorenzo TP and Steinberg BM: Elevation of the epidermal growth factor receptor and dependent signaling in human papillomavirus-infected laryngeal papillomas. Cancer Res 59: 968-974, 1999.

10. Tanabe T and Tohnai N: Cyclooxygenase isozymes and their gene structures and expression. Prostaglandins Other Lipid Mediat 68-69: 95-114, 2002.

11. Wu R, Coniglio SJ, Chan A, Symons MH and Steinberg BM: Up-regulation of Racl by epidermal growth factor mediates COX-2 expression in recurrent respiratory papillomas. Mol Med 13: 143-150, 2007.

12. Wu R, Abramson AL, Shikowitz MJ, Dannenberg AJ and Steinberg BM:Epidermal grow th factor induced cyclooxygenase-2 expression is mediated through phosphatidylinositol-3 kinase, not mitogen-activated protein/extracellular signal-regulated kinase kinase, in recurrent respiratory papillomas. Clin Cancer Res 11: 6155-6161, 2005.

13. Li JT, Wang H, Li W, Wang LF, Hou LC, Mu JL, Liu X, Chen HJ, Xie KL, Li NL and Gao CF: Anesthetic isoflurane posttreatment attenuates experimental lung injury by inhibiting inflammation and apoptosis. Mediat Inflamm 2013: 108928, 2013.

14. Wang H, Fan J, Li NL, Li JT, Yuan SF, Yi J, Wang L, Chen JH, Lv YG, Yao Q, et al: A subanesthetic dose of isoflurane during postconditioning ameliorates zymosan-induced neutrophil inflammation lung injury and mortality in mice. Mediat Inflamm 2013: 479628, 2013.

15. Kvolik S, Glavas-Obrovac L, Bares V and Karner I: Effects of inhalation anesthetics halothane, sevoflurane and isoflurane on human cell lines. Life Sci 77: 2369-2383, 2005.

16. Wang H, Wang L, Li NL, Li JT, Yu F, Zhao YL, Wang L, Yi J, Wang L, Bian JF, et al: Subanesthetic isoflurane reduces zymosan-induced inflammation in murine kupffer cells by inhibiting ROS-activated p38 MAPK/NF-кB signaling. Oxid Med Cell Longev 2014: 851692, 2014.

17. Steinberg BM, Abramson AL and Meade RP: Culture of human laryngeal papilloma cells in vitro. Otolaryngol Head Neck Surg 90: 728-735, 1982.

18. Kawaraguchi Y, Horikawa YT, Murphy AN, Murray F, Miyanohara A, Ali SS, Head BP, Patel PM, Roth DM and Patel HH: Volatile anesthetics protect cancer cells against tumor necrosis factor-related apoptosis-inducing ligand-induced apoptosis via caveolins. Anesthesiology 115: 499-508, 2011.

19. Livak KJ and Schmittgen TD: Analysis of relative gene expression data using real-time quantitative PCR and the 2(-Delta Delta C(T)) Method. Methods 25: 402-408, 2001.

20. Olson PN, Bowen RA, Behrendt MD, Olson JD and Nett TM: Validation of radioimmunoassays to measure prostaglandins F2 alpha and E2 in canine endometrium and plasma. Am J Vet Res 45: 119-124, 1984

21. Stoeck A, Gast D, Sanderson MP, Issa Y, Gutwein P and Altevogt P: L1-CAM in a membrane-bound or soluble form augments protection from apoptosis in ovarian carcinoma cells. Gynecol Oncol 104: 461-469, 2007.

22. Harris RE: Cyclooxygenase-2 (cox-2) and the inflammogenesis of cancer. Subcell Biochem 42: 93-126, 2007.

23. Turini ME and DuBois RN: Cyclooxygenase-2: A therapeutic target. Annu Rev Med 53: 35-57, 2002.

24. Robinson AB, Das SK, Bruegger DE, Hoover LA and Sanford TR: Characterization of cyclooxygenase in laryngeal papilloma by molecular techniques. Laryngoscope 109: 1137-1141, 1999.

25. Banerjee AG, Gopalakrishnan VK, Bhattacharya I and Vishwanatha JK: Deregulated cyclooxygenase-2 expression in oral premalignant tissues. Mol Cancer Ther 1: 1265-1271, 2002.

26. Chan G, Boyle JO, Yang EK, Zhang F, Sacks PG, Shah JP, Edelstein D, Soslow RA, Koki AT, Woerner BM, et al: Cyclooxygenase-2 expression is up-regulated in squamous cell carcinoma of the head and neck. Cancer Res 59: 991-994, 1999.

27. Ranelletti FO, Almadori G, Rocca B, Ferrandina G, Ciabattoni G, Habib A, Galli J, Maggiano N, Gessi M and Lauriola L: Prognostic significance of cyclooxygenase-2 in laryngeal squamous cell carcinoma. Int J Cancer 95: 343-349, 2001. 
28. Kulkarni S, Rader JS, Zhang F, Liapis H, Koki AT, Masferrer JL, Subbaramaiah K and Dannenberg AJ: Cyclooxygenase-2 is overexpressed in human cervical cancer. Clin Cancer Res 7: 429-434, 2001.

29. Golijanin D, Tan JY, Kazior A, Cohen EG, Russo P, Dalbagni G, Auborn KJ, Subbaramaiah K and Dannenberg AJ: Cyclooxygenase-2 and microsomal prostaglandin E synthase-1 are overexpressed in squamous cell carcinoma of the penis. Clin Cancer Res 10: 1024-1031, 2004.

30. Wada T and Penninger JM: Mitogen-activated protein kinases in apoptosis regulation. Oncogene 23: 2838-2849, 2004.

31. Arun B and Goss P: The role of COX-2 inhibition in breast cancer treatment and prevention. Semin Oncol 31 (2 Suppl 7): S22-S29, 2004

32. Tsujii M, Kawano $\mathrm{S}$ and DuBois RN: Cyclooxygenase-2 expression in human colon cancer cells increases metastatic potential. Proc Natl Acad Sci USA 94: 3336-3340, 1997.

33. Krysan K, Dalwadi H, Sharma S, Põld M and Dubinett S Cyclooxygenase 2-dependent expression of surviving is critical for apoptosis resistance in non-small cell lung cancer. Cancer Res 64: 6359-6362, 2004.
34. Subbmaramiah K and Dannenberg AJ: Cyclooxygenase 2: A molecular target for cancer prevention and treatment. Trends Pharmacol Sci 24: 96-102, 2003.

35. Loop T, Dovi-Akue D, Frick M, Roesslein M, Egger L, Humar M, Hoetzel A, Schmidt R, Borner C, Pahl HL, et al: Volatile anesthetics induce caspase-dependent, mitochondria-mediated apoptosis in human T lymphocytes in vitro. Anesthesiology 102: $1147-1157,2005$

36. Aravindan N, Cata JP, Hoffman L, Dougherty PM, Riedel BJ, Price KJ and Shaw AD: Effects of isoflurane, pentobarbital and urethane on apoptosis and apoptotic signal transduction in rat kidney. Acta Anaesthesiol Scand 50: 1229-1237, 2006.

37. Zhang Y, Dong Y, Wu X, Lu Y, Xu Z, Knapp A, Yue Y, Xu T and Xie Z: The mitochondrial pathway of anesthetic isoflurane induced apoptosis. J Biol Chem 285: 4025-4037, 2010.

38. Cory S and Adams JM: The Bcl2 family: Regulators of the cellular life-or-death switch. Nat Rev Cancer 2: 647-656, 2002.

39. Orrenius S, Zhivotovsky B and Nicotera P: Regulation of cell death: The calcium-apoptosis link. Nat Rev Mol Cell Biol 4: $552-565,2003$. 